\title{
Research on the Current Situation and Countermeasures of College Students' Mobile Internet in Northeast Sichuan
}

\author{
Shi Ming-na ${ }^{1, \mathrm{a} *}$; Zhang $\mathrm{Hao}^{2, \mathrm{~b}}$ \\ ${ }^{1}$ College of music and Performing Arts of Sichuan University of Arts and Science, China \\ ${ }^{2}$ Personnel division of Sichuan University of Arts and Science, China
}

\begin{abstract}
Today, a large number of College students prefer to use mobile Internet rather than use traditional Internet, it is necessary to analysis the status of their mobile Internet using. The research objectives are college students in northeast Sichuan Province. Using the method of investigation, interview and data statistics, the paper explores the current situation of mobile Internet using in this group, especially the negative impact caused by the use of the mobile Internet. The paper also puts forward the countermeasure and strategy, in order to promote the healthy development of College Students.
\end{abstract}

Keywords: Mobile Internet; College students; Northeast Sichuan Province

\section{Preface}

The rapid development of mobile Internet influents contemporary college students' life and learning. We should view this influence dialectically. Mobile Internet is benefit to the improvement of students indeed, such as the speed and span of learning. However, we should pay more attention to the negative impact of the mobile Internet on college students, such as indulging in online games and the over dependence of Internet chat. As a scientific research project of Sichuan University of Arts and Science (No. 2016SZ003Y), the study makes an overall investigation on the status of college students' mobile Internet usage from the scope of northeast Sichuan province, puts forward the corresponding ideological strategy, in order to promote the healthy development of college students.

\section{Investigation On The Situation Of College Students' Mobile Internet Usage In Northeast} Sichuan Province

A. Mobile Internet media usage

Table 1 The use of mobile Internet hardware media

\begin{tabular}{|l|l|l|l|}
\hline & Intelligent mobile phone & Notebook & Tablet PC \\
\hline Frequency & 987 & 677 & 373 \\
\hline Effective percentage $(\%)$ & 96.35 & 76.51 & 31.12 \\
\hline
\end{tabular}

Table 2 The use of mobile Internet software media

\begin{tabular}{|l|l|l|l|l|l|l|}
\hline & Chat & Photograph & News & Game & Video & Others \\
\hline Frequency & 936 & 232 & 187 & 873 & 902 & 112 \\
\hline Effective percentage(\%) & 73.63 & 32.47 & 22.94 & 59.31 & 65.97 & 15.67 \\
\hline
\end{tabular}

B. Time of Mobile Internet usage

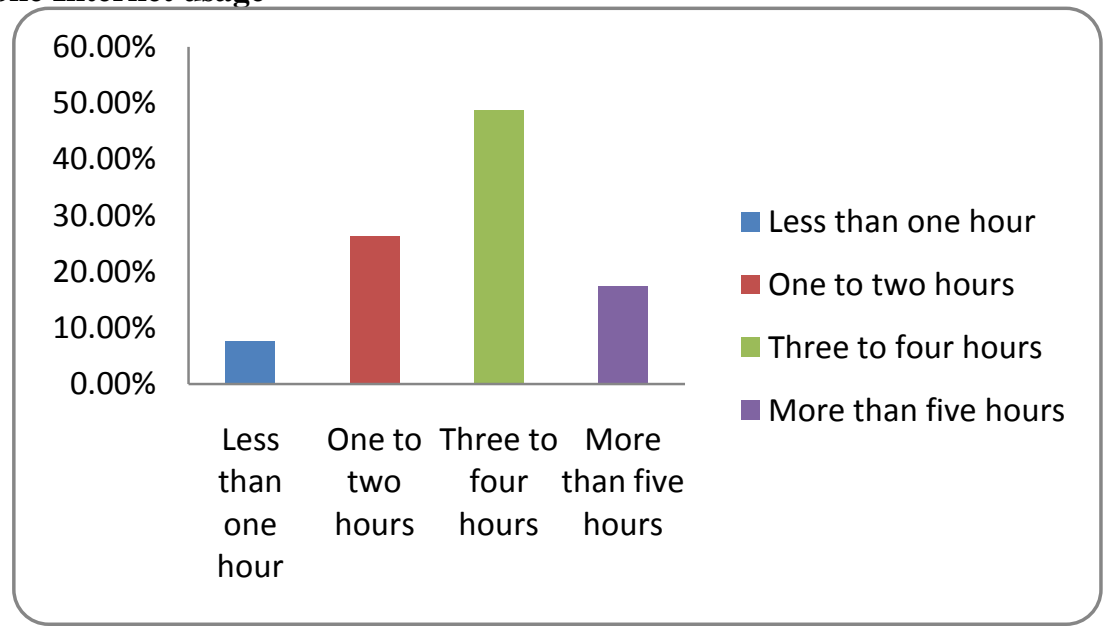

Figure 1 Time of Mobile Internet usage 
The data analysis shows that nearly $90 \%$ of the sample uses mobile Internet every day, further analysis shows that $48.73 \%$ of the college students use mobile Internet 3-4 hours every day, $26.23 \%$ of students use it for 1-2 hours, $17.39 \%$ even use it for more than 5 hours. Based on the above data analysis, the author believes that the mobile Internet occupies an important position in the life and study time of the college students in northeast Sichuan province.

\section{Mobile Internet usage in different grades}

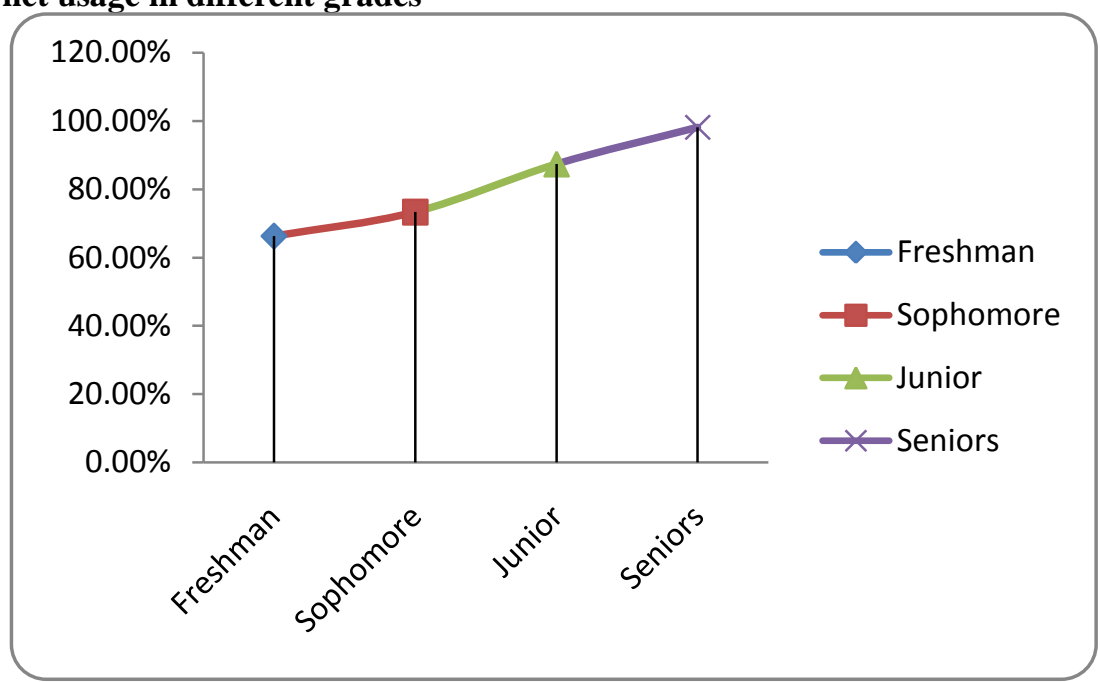

Figure 2 Mobile Internet usage in different grades

The survey on mobile Internet usage in different grades shows an obvious increasing trend from the first year of college students to the fourth grade students. The freshmen in mobile Internet usage proportion is $66.23 \%$, the usage ratio of second grade students is $73.31 \%$, and it reaches $87.34 \%$ in third grade, and number rise to the top in fourth grade. Mobile Internet has become an important part of learning and life of college students.

\section{Survey on attention and purpose of Mobile Internet usage}

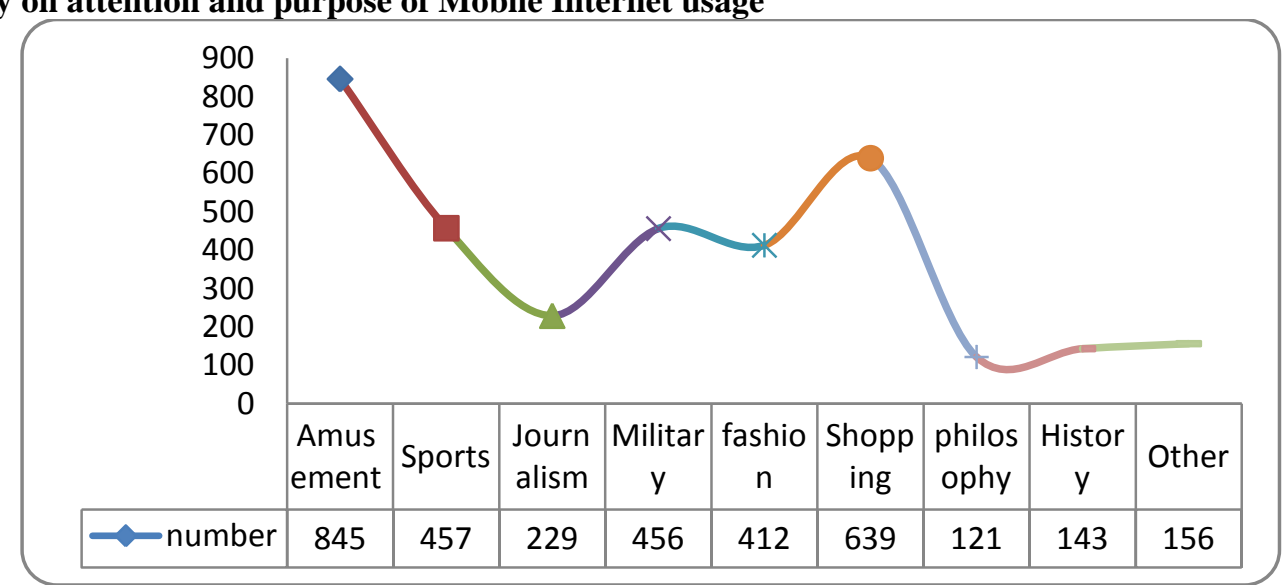

Figure 3 Survey on attention of Mobile Internet usage

The focus of college students in northeast Sichuan province is various, the survey found that their concern point involves extensive contents, including news, sports, entertainment, military, fashion, shopping, philosophy, history and so on. The survey also found that college students in northeast Sichuan province focus too much on entertainment and shopping, from Figure 3, 845 of people choose to focus on entertainment, 639 people choose to focus on shopping, the two groups are at the peak in the curve graph. News, history, philosophy and other aspects get less attention. 


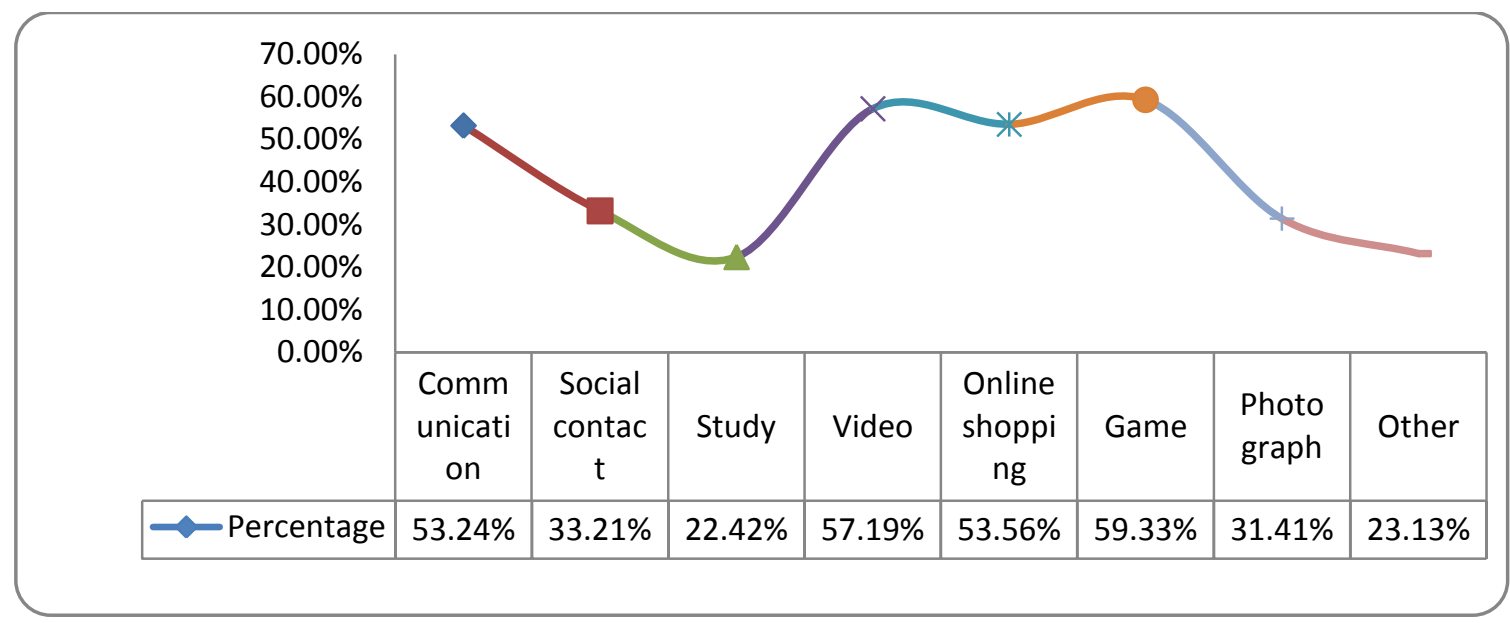

Figure 4 Survey on purpose of Mobile Internet usage

The purpose of Mobile Internet usage shows that the mobile Internet has be mainly used for the game, accounted for 59.33\%, ranked first, and followed for video, online shopping and communication, accounted for $57.19 \%, 53.56 \%$ and $53.24 \%$, which further proves that the mobile Internet attention content focus on entertainment options. The purpose for learning only figures $22.42 \%$, which also proved that the content of "learning" "philosophy" and "history" draws less attention.

\section{E. Dependence of Mobile Internet}

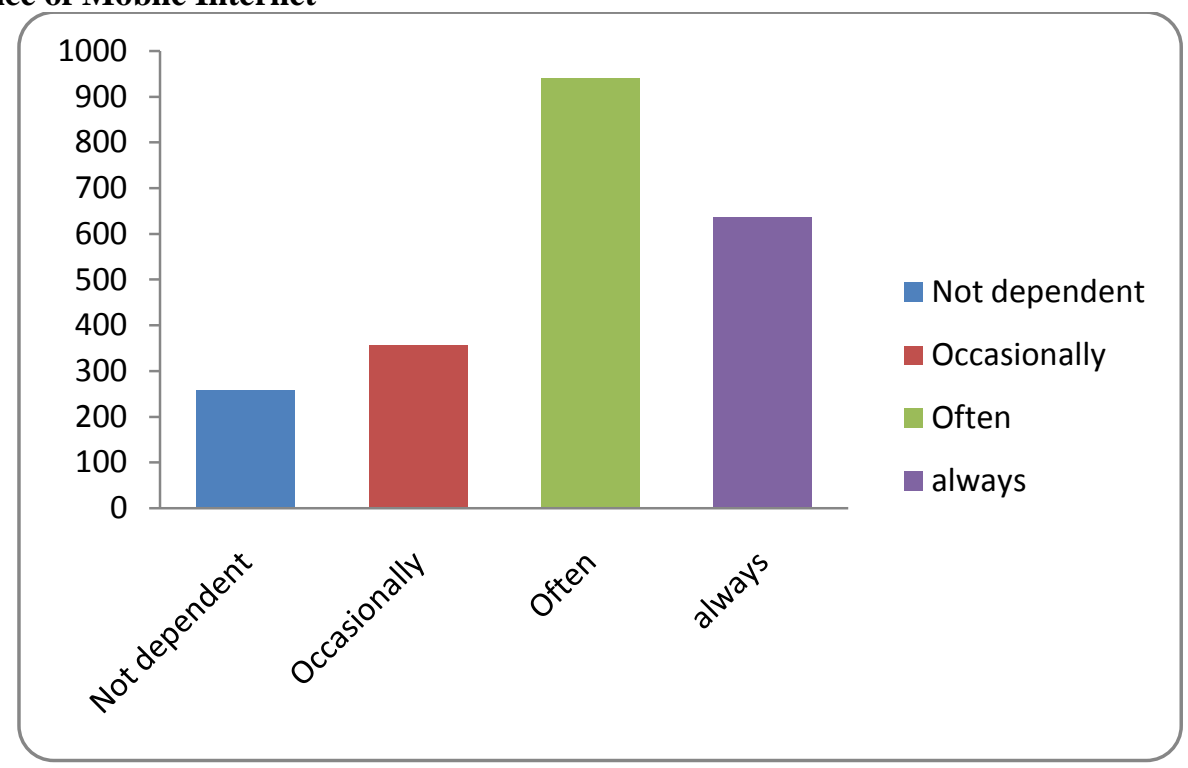

Figure 5 Dependence of Mobile Internet

Survey on the dependence of Mobile Internet shows that "often dependence" accounts for 939, "always dependence" accounted for 635, from the overall, the dependence of college students in northeast Sichuan province is very high, "not dependence" and "occasionally dependence" are largely below the two groups above, which also reflects the high demand for mobile Internet of college students.

\section{The Negative Impact Caused By Mobile Internet On College Students In Northeast Sichuan}

\section{A. On the physical health of college Students}

\section{Province}

The mobile Internet usage of college students in northeast Sichuan Province is at a high level, excessive usage of mobile Internet can cause damage to the students' eyesight---eyes are in a state of exhaustion for a long time, and they can't have an effectively rest. Secondly, high frequency of the use of mobile Internet will produce some parts of the body muscle strain, such as spondylosis and mouse hand. Third, the radiation problem of mobile Internet can't be avoided. The long-term exposure before the screen of electronic equipment will cause gene mutation, as well as nervous system disorders and neurasthenia. 


\section{B. On the mental health of college Students}

Excessive use of mobile Internet will cause series of psychological health problems of college students. Students spend too much time on chatting in virtual world instead of communicating face-to-face with their friends and relatives in reality. A feeling of alienation between them gradually rise because they all live in their own virtual space. Excessive use of mobile Internet also cause a dependency on mobile phones and computers, without these devices they may become anxious, manic, uneasy.

\section{Influence on College Students' learning}

Excessive use of mobile Internet will directly affect the learning of college students. First of all, the excessive time consumption in the mobile Internet, will inevitably lead to the decrease of the learning time. They are addicted to games and TV drama, which lead them have less time to learn. The survey also shows that many college students in the class is not willing to keep their mobile phone in a closed state, chatting online and playing games is a regular phenomenon in the class. Secondly, much attention and usage of the mobile Internet lead college students lose their intention of obtaining different kinds of knowledge on mobile Internet, instead, they devote time which should be used on learning on shopping, film, games and TV drama. They can't aware the fact---Mobile Internet is a tool, but not the purpose.

\section{Suggestion}

\section{A. Renew the idea of ideological education and realize the interaction of guidance}

Mobile Internet is a trend of the social development, our ideological education management should conform to the current development. Aiming at the current situation of college students, we should update the ideological education concept which is too old at present. We need to stand in an equal position of the students to communicate with them. According to the status of college students, ideological education of managers can make a good use of instant messaging software, such as WeChat, QQ, micro-blog and other means to integrate this group. Exchange of ideas between guidance and students are necessary, which could help college students achieve self-management.

\section{B. Improve working methods and enhance ability of mobile Internet usage}

The work method of ideological educators is very important. A good work method can directly affect the college students. In view of the current situation of mobile Internet use, ideological educators should cultivate the ability of using mobile Internet devices. We can obtain relevant information from these tools, in order to grasp the students' immediate dynamic and intellectual development. At the same time, we should put forward positive methods, to guide the students to make full use of mobile Internet on learning and the acquisition of information.

\section{Use mobile Internet to achieve the era of ideological guidance}

At present, college students' use of mobile Internet has become a sub culture. In view of this cultural phenomenon, we should not feel confused---the present situation is generated, rooted in the development of the times and the reality of life, we should dialectically examine this sub culture problem. Mobile Internet media has the characteristics of flexible, amiable and easy of approach, we should make full use of Internet new media, develop its positive energy, expand the connotation of education. Only in this way can we guide the identity and self-realization of the sub culture.

\section{Acknowledgements}

This work is supported by the scientific research project of Sichuan University of Arts and Science (item number: 2016SZ003Y)

\section{Reference}

[1]. Chengrong Liu. Ideological and political education of college students based on mobile Internet technology, J. Education and occupation, 2014(7) : 51-52.

[2]. Kaishan Jiao. Loneliness and the use of mobile Internet, J. Youth Studies, 2003 (1)4-8.

[3]. Hongbo Liu. On the characteristics of mobile Internet usage of Contemporary College Students, J. Journal of changsha university,2015(4):135-137.

[4]. Xiaohui Wu, Shouxin Zhang, Qi Li. Investigation on mobile Internet usage of College Students, J. New Media Studies,2016(7):51-52.

[5]. Siwen Liu. The impact of mobile Internet on College Students' Ideological and political education and Its Countermeasures, J.2016(10):66-67. 